\title{
INFLUENCE OF MINIMALLY INVASIVE LAPAROSCOPIC EXPERIENCE SKILLS ON ROBOTIC SURGERY DEXTERITY
}

\author{
Influência da experiência da cirurgia laparoscópica na destreza da cirurgia robótica \\ Marcos BELOTTO ${ }^{1,3 \odot}$, Larissa COUTINHO ${ }^{2 \odot}$, Adhemar M PACHECO-JR ${ }^{1 \oplus}$, Anuar I. MITRE ${ }^{3 \odot}$, Eduardo \\ Antunes da FONSECA ${ }^{3 \odot}$
}

ABSTRACT - Background: It is unclear if there is a natural transition from laparoscopic to robotic surgery with transfer of abilities. Aim: To measure the performance and learning of basic robotic tasks in a simulator of individuals with different surgical background. Methods: Three groups were tested for robotic dexterity: a) experts in laparoscopic surgery $(n=6)$; b) experts in open surgery $(n=6)$; and c) non-medical subjects $(n=4)$. All individuals were aged between $40-50$ years. Five repetitions of four different simulated tasks were performed: spatial vision, bimanual coordination, hand-foot-eye coordination and motor skill. Results: Experts in laparoscopic surgery performed similar to non-medical individuals and better than experts in open surgery in three out of four tasks. All groups improved performance with repetition. Conclusion: Experts in laparoscopic surgery performed better than other groups but almost equally to non-medical individuals. Experts in open surgery had worst results. All groups improved performance with repetition.

HEADINGS: Robotic. Laparoscopy. Motor skills. High fidelity simulation training.

RESUMO - Racional: É incerto se há transferência natural de habilidades da cirurgia laparoscópica para a robótica. Objetivo: Avaliar o desempenho e aprendizado de tarefas em plataforma robótica simulada em indivíduos com diferentes conhecimentos em cirurgia. Método: Três grupos de indivíduos foram testados quanto à habilidade robótica: a) especialistas em cirurgia laparoscópica $(n=6)$; b) especialista em cirurgia convencional $(n=6) ;$ e c) indivíduos não médicos. A idade variou em todo grupo entre 40-50 anos. Cinco repetições de quatro tarefas simuladas foram realizadas: visão espacial, coordenação bimanual, coordenação mão-pé-olho e destreza manual. Resultados: Especialistas em cirurgia laparoscópica tiveram desempenho semelhante aos indivíduos não médicos e melhor que os especialistas em cirurgia convencional em três das quatro tarefas. Todos os grupos melhoraram desempenho com repetições. Conclusão: Especialistas em cirurgia laparoscópica desempenharam melhor que os outros grupos, mas quase igualitariamente aos indivíduos não médicos. Especialista em cirurgia convencional apresentaram os piores resultados. Todos os grupos melhoraram com as repetições.

DESCRITORES - Robótica. Laparoscopia. Habilidades motoras. Treinamento de simulação de alta fidelidade.

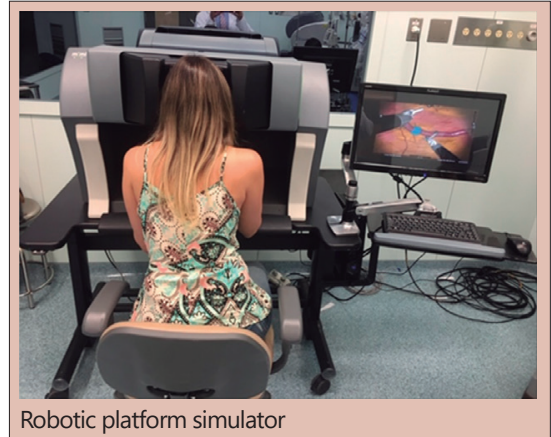

\section{Central message}

Robotic surgery demands skills not automatically transferred from open surgery dexterity but learned in part by laparoscopic surgery and natural movements.

Perspective
Training is an important part of surgical learning.
Simulators are valuable tools for learning. Both
laparoscopic surgeons and specially those trained
in open surgery only are encouraged to practice in
simulators.

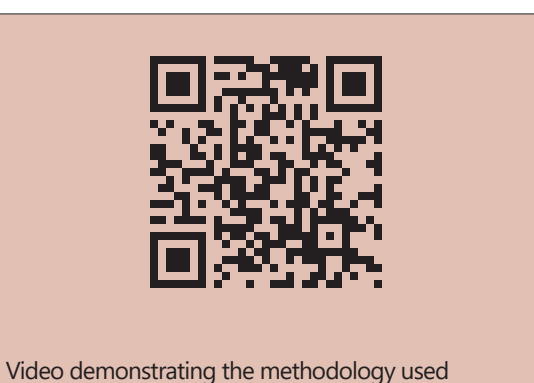

How to cite this article: Belotto M, Coutinho L, Pacheco-Jr AM, Mitre Al, Da Fonseca EA. Influence of minimally invasive laparoscopic experience skills on robotic surgery dexterity. ABCD Arq Bras Cir Dig. 2021;34(3):e1604. DOI: /10.1590/0102-672020210001e1604

Correspondence:

Marcos Belotto

E-mail: marcbelotto@hotmail.com
Financial source: This study was financed in part by the Coordenação de Aperfeiçoamento de Pessoal de Nível Superior - Brasil (CAPES) - Finance Code 001

Conflict of interest: none

Received for publication: 19/10/2020

Accepted for publication: 04/02/2021 
INTRODUCTION

$\mathrm{R}$ obotic surgery may be considered by some a natural evolution of laparoscopic surgery; however, there are noteworthy differences between these two minimally invasivetechniques ${ }^{20}$. These dissimilarities maylead to the assumption that there is no transference of laparoscopic abilities to the robotic platform but a need to abandon some previous aptitudes to learn new skills ${ }^{33}$.

Robotic skills can be adequately trained and evaluated by realist simulators ${ }^{19}$. Previous studies compared robotic skills in individuals with different laparoscopic backgrounds to show in its majority similar results for experts and novices ${ }^{26,33}$. The similarity of performance suggests a human natural ability to manipulate robotic instruments, i.e., robotic platform is apt to capture all-natural movements. These studies, however, compared individuals from different generations (usually medical students or residents vs. senior surgeons) bringing advantages to the neophytes more used to technology and videogames whose abilities are transferable to simulators ${ }^{28}$.

We believe that a protocol to evaluate if there is a natural transition of laparoscopic skills to robotic platform or a better ability of surgical robots to capture human natural movements must compare surgeons with different degrees of laparoscopic experience and individuals unfamiliar to surgical techniques and surgical simulation all from the same generation.

This study aims to measure the performance and learning of basic robotic tasks in a simulator of individuals with different laparoscopic background and non-medical individuals.

\section{METHOD}

The protocol was approved by local IRB and informed consent was obtained from all individuals.

\section{Population}

Three groups of individuals from 40-50years of age, without previous robotic surgery experience were recruited: A) group 1 $(n=6,100 \%$ males), age 45 (41-47) years), experts in laparoscopic surgery, over five years and over 100 complex procedures, all gastrointestinal surgeons; B) group $2(n=6,83 \%$ males), age 44 (43-44) years), experts in open surgery, over five years, over 100 complex procedures, less than 10 simple laparoscopic procedures per year, no performance of complex laparoscopic procedures, all gastrointestinal surgeons; C) group 3 ( $n=4,50 \%$ males), age $42(41-45)$ years, two lawyers, one publicist, one financial analyst), individuals whose professions are apart from healthcare and robotic platforms.

\section{Simulator}

A realistic robotic simulator was used to assess robotic abilities (Mimic, Intuitive Surgery, Sunnyvale). The simulator has two manual joysticks and seven pedal switches. Individuals adopt a position similar to the real robotic platform commanding simulated scenarios depicting preloaded basic tasks. Performance was measured using a score from 0 to 100 considering time to perform the task, instruments collision, manual dexterity, force applied to the instruments and economy of movement.

Individuals were instructed to watch an educative video resident in the system and perform five repetitions of four basic tasks: 1) "camera targeting": individuals were asked to step on the camera pedal and focus on the targets using the joysticks; the task evaluated spatial vision; 2) "ring walk": participants were asked to transfer rings from one point to the other using both hands; this task evaluated bimanual skills; 3) "energy switching": individuals were asked to apply different coagulating energies in random targets using two different pedals, this task evaluated hand-feet-eyes coordination; and 4) "pick \& place": individuals were asked to sort objects according to colors; this task evaluated motor skills (Figure 1).

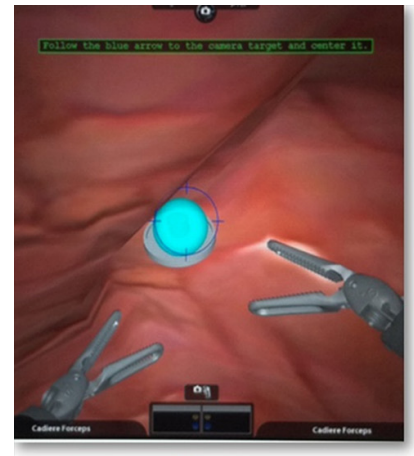

A

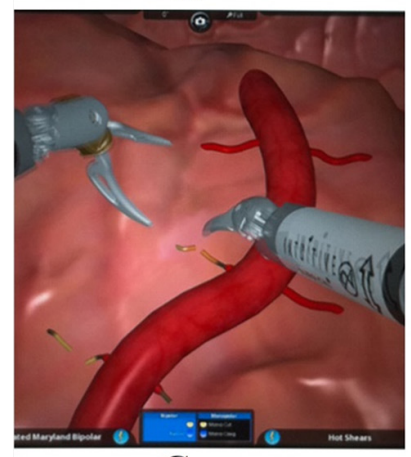

C

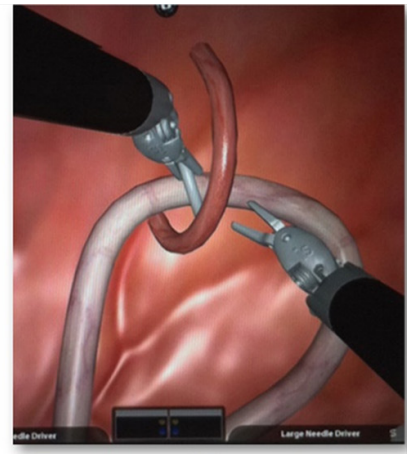

B

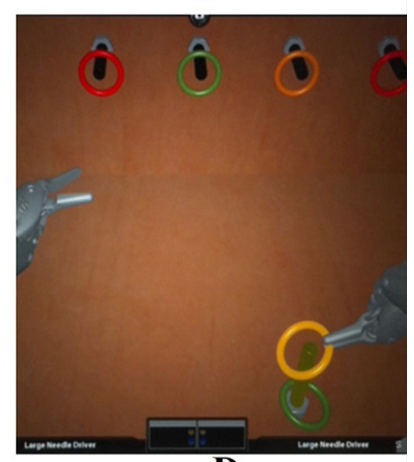

$\mathbf{D}$
FIGURE 1 - Simulated tasks at the robotic platform: A) camera targeting; B) ring walk; C) energy switching; D) pick \& place

\section{Statistical analysis}

Variables were expressed as median (quartile 25-75), $p<0.05$ was set as significant. Mann-Whitney and Kruskall-Whallis were used to compared medians; Fisher test was used to compare proportions and Durbin-Watson test to evaluate temporal tendency.

\section{RESULTS}

There were no statistical differences among groups on gender $(p=0.2)$ and age $(p=0.9)$. All individuals completed the tasks.

Performance scores for the three groups are depicted in Table 1. Experts in laparoscopic surgery performed similar to non-medical individuals and better than experts in open surgery in three out of four tasks. Temporal tendency of performance scores is expressed in Figure 2. All groups improved performance with repetition.

TABLE 1 - Performance scores for simulated basic robotic tasks

\begin{tabular}{|c|c|c|c|c|}
\hline Task & $\begin{array}{c}\text { Group } 1 \\
\text { (surgeons } \\
\text { experienced in } \\
\text { laparoscopic } \\
\text { surgery) }\end{array}$ & $\begin{array}{c}\text { Group } 2 \\
\text { (surgeons } \\
\text { experienced } \\
\text { in open } \\
\text { surgery) }\end{array}$ & $\begin{array}{c}\text { Group } \\
3 \text { (non- } \\
\text { medical - } \\
\text { controls) }\end{array}$ & $\begin{array}{c}\text { Comparison } \\
\text { among } \\
\text { groups }\end{array}$ \\
\hline $\begin{array}{l}\text { Camera } \\
\text { targeting }\end{array}$ & $\begin{array}{c}98(69-100) \\
{[53-100]}\end{array}$ & $\begin{array}{c}73(47-96) \\
{[13-100]}\end{array}$ & $\begin{array}{c}97(72-98) \\
{[34-100]}\end{array}$ & $\begin{array}{c}1 \times 2 p<0.001 \text { * } \\
1 \times 3 p=0.2 \\
2 \times 3 p=0.02 \text { * }\end{array}$ \\
\hline $\begin{array}{l}\text { Ring } \\
\text { walk }\end{array}$ & $\begin{array}{c}78(42-88) \\
{[19-96]}\end{array}$ & $\begin{array}{c}61(38-67) \\
{[10-95]}\end{array}$ & $\begin{array}{c}85(74-91) \\
{[30-96]}\end{array}$ & $\begin{array}{c}1 \times 2 p=0.08 \\
1 \times 3 p=0.1 \\
2 \times 3 p<0.001 \text { * }\end{array}$ \\
\hline $\begin{array}{c}\text { Energy } \\
\text { switching }\end{array}$ & $\begin{array}{c}69(47-810 \\
{[24-91]}\end{array}$ & $\begin{array}{c}44(19-56) \\
{[0-97]}\end{array}$ & $\begin{array}{c}52(36-64) \\
{[27-84]}\end{array}$ & $\begin{array}{c}1 \times 2 p<0.001 \text { * } \\
1 \times 3 p=0.02 \text { * } \\
2 \times 3 p=0.09\end{array}$ \\
\hline $\begin{array}{l}\text { Pick \& } \\
\text { place }\end{array}$ & $\begin{array}{c}81(70-90) \\
{[48-94]}\end{array}$ & $\begin{array}{c}65(56-76) \\
{[35-93]}\end{array}$ & $\begin{array}{c}83(74-88) \\
{[57-94]}\end{array}$ & $\begin{array}{c}1 \times 2 p<0.001 \text { * } \\
1 \times 3 p=0.8 \\
2 \times 3 p<0.001 \text { * }\end{array}$ \\
\hline
\end{tabular}

Variables are expressed as median (quartile $25-75$ ); ${ }^{*}=$ statistical significant 


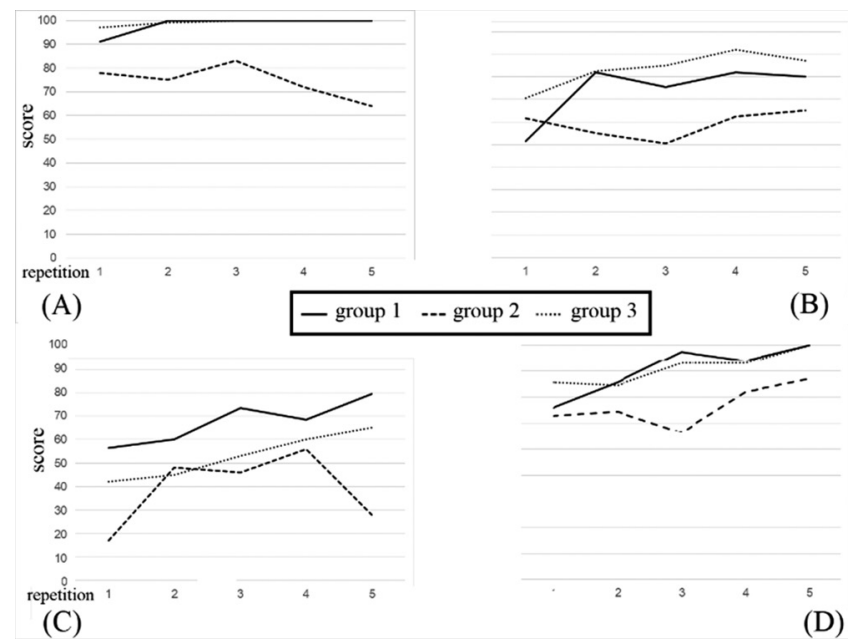

FIGURE 2 - Temporal tendency of performance scores for basic simulated robotic skills: A) camera targeting; B) ring walk; C) energy switching; D) pick \& place

\section{DISCUSSION}

Differences between laparoscopic and robotic learning

There are pros and cons associated to robotic surgery in comparison to laparoscopic surgery; however, most of them are directed towards the operator with an indirect benefit to the patient only. This study considers that are technical differences between these two types of minimally invasive approaches, not only for the performance of the operation such as the process of docking, neither the 3-D vision or articulated instruments that are available in laparoscopic surgery as well ${ }^{1}$, but especially the lack of tactile sensation and the reproduction of writs natural movements without a fulcrum.

Laparoscopic surgery allows physical contact between the hands of the surgeon and the anatomical structure through long and non-flexible instruments ${ }^{34}$. Although not perfect, this brings a haptic feedback. This imperfection brings the need for learning. Experient surgeons have increased ability in force control of laparoscopic instruments as compared to novices ${ }^{29}$. Oppositely, surgeons and patients are distant in robotic surgery. Some technological advances try to simulate tactile or replace it with other stimuli such as sounds ${ }^{2}$, but this is not reality in most systems. Interestingly, the lack of haptic sensation may be compensated with experience ${ }^{6}$. The simulator used in this study scores the excessive use of force applied to instruments. We did not analyze mathematically the numbers due to the low statistical power for sub-analysis in a small population, but excessive force use was common in almost all participants from all three groups.

Different previous studies in simulators showed similar performance in the execution of basic tasks for experienced laparoscopic surgeons and individuals in training (medical students or residents) ${ }^{18,21,23}$. The same was observed when experts in open surgery were compared to novices ${ }^{5}, 18$. Our results, in concordance with these studies, show some transfer of laparoscopic ability to robotic surgery since experts in laparoscopic surgery performed better than non-experts but in equality to controls. These facts suggest that the robotic platform may understand natural movements allowing controls to perform well and that some laparoscopic abilities (such as inverted movement due to fulcrum) may actually prevent surgeons from performing better than controls forcing to forget some automatic movements to relearn more natural actions. We opted to recruit individuals for the control group that are not linked to health sciences and choose basic not clinical tasks to be executed in order to evaluate natural abilities only. Similarly, we limited age of participants to avoid learned aptitudes with videogames and laic technology.

\section{curves}

Differences between robotic and laparoscopic learning

The learning curve for proficiency seems to be longer for laparoscopic surgery compared to robotic surgery (Table 2) although these studies may be criticized for several reasons: 1) only operative time is considered in most papers, not other parameters such as surgical complications; 2) surgeons with previous experience in the procedure via open or laparoscopy are tested; 3) curve is analyzed after a certain number of cases are operated not based on mathematical calculations; 4) bias of selection of cases for the beginning of experience; 5) expertise is evaluated comparing two periods of time arbitrarily defined; 6) robotic cases are usually more recent; etc. Our study, nonetheless, showed a strong tendency for all groups to learn and perform better even considering only five repetitions of the same task. This fact was also observed by others ${ }^{21}$ and it may show a real quick learning characteristic of robotic surgery.

TABLE 2 - Comparison between learning curves for laparoscopic vs. robotic surgery

\begin{tabular}{|l|c|c|c|}
\multicolumn{1}{c}{ Procedure } & $\begin{array}{c}\text { Laparoscopic } \\
\text { surgery }\end{array}$ & $\begin{array}{c}\text { Robotic } \\
\text { surgery }\end{array}$ & References \\
\hline Esophagectomy & $30-40$ & $20-26$ & $13,15,32,37$ \\
\hline Gastrectomy & $41-46$ & $20-25$ & $14,17,38$ \\
\hline Roux-em-Y gastric bypass & $100-500$ & $8-14$ & $3,4,8,9$ \\
\hline Pancreatectomy & $15-30$ & $10-40$ & $16,27,24,31$ \\
\hline Colectomy & $50-85$ & $30-44$ & $12,22,25,35$
\end{tabular}

\section{Ethics and robotic learning}

Simulators are a reality in several residence training programs ${ }^{36}$; however, there is an uncountable number of board certified surgeons unfamiliar with robotic surgery. Our protocol evaluated basic manual and coordination skills but, surprisingly, experienced surgeons scored less than $50 \%$ of the ideal goal. This shows that simulator training before clinical practice should be mandatory.

Innovation should be carefully tested before dissemination and it must be followed by adequate training to acquire proficiency ${ }^{11}$. Moreover, laboratory training was considered a precondition to consider surgical innovation ethical ${ }^{10}$.

Interestingly, simulators are not only useful for learning. Warming up in simulators brings enhanced performance ${ }^{7}$. Following principles of aviation applied to surgery ${ }^{30}$, surgeons should keep periodic training in simulators.

Our study has some limitations such as the small number of participants. The degree of significance of the findings; however, suggests that results were not jeopardized. Also, the tasks we selected may be criticizes. We tried to choose different abilities distant from clinical significance to avoid biases with the control group. The rigorous selection of participants all from the same age is a strong point of the study in our opinion and probably original.

\section{CONCLUSION}

Experts in laparoscopic surgery performed better than other groups but almost equally to non-medical individuals. Experts in open surgery had worst results. All groups improved performance with repetition. These findings may suggest that robotic surgery reproduce natural movements and it is prone to be quick learned although even experienced laparoscopic surgeons did not perform ideally initially. Surgeons inexperienced in minimally invasive surgery apparently need a longer training. 
REFERENCES

1. Abou-Haidar H, Al-Qaoud T, Jednak R, Brzezinski A, El-Sherbiny M, CapolicchioJP.Laparoscopic pyeloplasty: Initial experiencewith3Dvision laparoscopy and articulating shears. J Pediatr Urol. 2016 Dec;12(6):426 e1-426.e5. doi: 10.1016/j.jpurol.2016.08.027. Epub 2016 Oct 24. PMID: 27889223.

2. AmirabdollahianF, LivatinoS, VahediB,GudipatiR, SheenP, Gawrie-Mohan $\mathrm{S}$, Vasdev N. Prevalence of haptic feedback in robot-mediated surgery: a systematic review of literature. J Robot Surg. 2018 Mar;12(1):11-25. doi: 10.1007/s11701-017-0763-4. Epub 2017 Dec 1. PMID: 29196867.

3. Ayloo S, Fernandes E, Choudhury N. Learning curve and robot set-up/ operative timesin singly docked totally robotic Roux-en-Ygastric bypass SurgEndosc.2014May;28(5):1629-33.doi:10.1007/s00464-013-3362-0. Epub 2014 Jan 3. PMID: 24385247.

4. Buchs NC, Pugin F, Bucher P, Hagen ME, Chassot G, Koutny-Fong P, Morel P. Learning curve for robot-assisted Roux-en-Y gastric bypass. Surg Endosc. 2012Apr;26(4):1116-21. doi:10.1007/s00464-011-2008-3. Epub 2011 Nov 2. PMID: 22044973.

5. Cumpanas AA, Bardan R, Ferician OC, Latcu SC, Duta C, Lazar FO. Does previous open surgical experience have any influence on robotic surgery simulation exercises? Wideochir Inne Tech Maloinwazyjne. 2017 Dec;12(4):366-371. doi: 10.5114/wiitm.2017.72320. Epub 2017 Dec 29. PMID: 29362651; PMCID: PMC5776487

6. Cundy TP, Gattas NE, Yang GZ, Darzi A, Najmaldin AS. Experience related factors compensateforhapticlossin robot-assisted laparoscopicsurgery. J Endourol. 2014 May;28(5):532-8. doi: 10.1089/end.2013.0671. Epub 2014 Feb 7. PMID: 24397464

7. da Cruz JAS, Dos Reis ST, Cunha Frati RM, Duarte RJ, Nguyen H, Sroug $M$, Passerotti CC. Does Warm-Up Training in a Virtual Reality Simulator Improve Surgical Performance? A Prospective Randomized Analysis. SurgEduc.2016Nov-Dec;73(6):974-978.doi:10.1016/j.jsurg.2016.04.020. Epub 2016 May 24. PMID: 27233673.

8. deRooijT,CiprianiF, RawashdehM, vanDierenS,BarbaroS,AbuawwadM vanHilstJ,FontanaM, BesselinkMG,AbuHilalM.Single-SurgeonLearning Curvein 111 Laparoscopic Distal Pancreatectomies:DoesOperativeTime Tell the Whole Story? J Am Coll Surg. 2017 May;224(5):826-832.e1. doi: 10.1016/j.jamcollsurg.2017.01.023. Epub 2017 Jan 24. PMID: 28126547

9. El-Kadre L, Tinoco AC, Tinoco RC, Aguiar L, Santos T. Overcoming the learning curve of laparoscopic Roux-en-Y gastric bypass: a 12-year experience.Surg ObesRelatDis.2013Nov-Dec;9(6):867-72.doi:10.1016/j. soard.2013.01.020. Epub 2013 Feb 11. PMID: 23499192.

10. FerreresAR, PattiM. Ethical Issuesinthelntroduction of New Technologies: From Mis to POEM. World J Surg. 2015 Jul;39(7):1642-8. doi: 10.1007/ s00268-015-3067-8. PMID: 25894402.

11. FisichellaPM, DeMeesterSR, HungnessE, PerrettaS, SoperNJ, Rosemurgy A, Torquati A, Sachdeva AK, Patti MG. Emerging Techniques in Minimally InvasiveSurgery.Prosand Cons.J GastrointestSurg.2015Jul;19(7):1355-62. doi: 10.1007/s11605-015-2766-7. Epub 2015 Feb 13. PMID: 25678255.

12. Guend H, Widmar M, Patel S, Nash GM, Paty PB, Guillem JG, Temple LK, Garcia-Aguilar J, Weiser MR. Developing a robotic colorectal cancer surgery program: understanding institutional and individual learning curves. Surg Endosc. 2017 Jul;31(7):2820-2828. doi: 10.1007/s00464016-5292-0. Epub 2016 Nov 4. PMID: 27815742; PMCID: PMC5418100.

13. Guo W, Zou YB, Ma Z, Niu HJ, Jiang YG, Zhao YP, Gong TQ, Wang RW (2013) One surgeon's learning curve for video-assisted thoracoscopic esophagectomyforesophageal cancerwith the patientinlateral position: how many cases are needed to reach competence? Surg Endosc. 27(4):1346-52. doi: 10.1007/s00464-012-2614-8.

14. Harrison LE, Yiengpruksawan A, Patel J, Itskovich A, Lee B, Korst R. Robotic gastrectomy and esophagogastrectomy: A single center experience of 105 cases. J Surg Oncol. 2015 Dec;112(8):888-93. doi: 10.1002/jso.24073. Epub 2015 Oct 21. PMID: 26487124

15. Hernandez JM, Dimou F, Weber J, Almhanna K, Hoffe S, Shridhar R Karl R, Meredith K. Defining the learning curve for robotic-assisted esophagogastrectomy. J Gastrointest Surg. 2013 Aug;17(8):1346-51. doi: 10.1007/s11605-013-2225-2. Epub 2013 May 21. PMID: 23690208.

16. Hua Y, Javed AA, Burkhart RA, Makary MA, Weiss MJ, Wolfgang CL, He J. Preoperative risk factors for conversion and learning curve of minimally invasive distal pancreatectomy. Surgery. 2017 Nov; 162(5):1040-1047. doi: 10.1016/j.surg.2017.07.014. Epub 2017 Sep 1. PMID: 28866314.

17. Huang KH, Lan YT, Fang WL, Chen JH, Lo SS, Li AF, Chiou SH, Wu CW, Shyr YM. Comparison of the operative outcomes and learning curves between laparoscopic and robotic gastrectomy for gastric cancer. PLoS One. 2014 Oct 31;9(10):e111499. doi: 10.1371/journal.pone.0111499. PMID: 25360767; PMCID: PMC4216064.

18. Kowalewski KF, Schmidt MW, Proctor T, Pohl M, Wennberg E, Karadza E, Romero P, Kenngott HG, Müller-Stich BP, Nickel F (2018) Skills in minimallyinvasiveand opensurgeryshowlimited transferabilitytorobotic surgery: results from a prospective study. Surg Endosc. 32(4):1656-1667. doi: 10.1007/s00464-018-6109-0.
19. Kumar A, Smith R, Patel VR. Current status of robotic simulators in acquisition of robotic surgical skills. Curr Opin Urol. 2015 Mar;25(2):16874. doi: 10.1097/MOU.0000000000000137. PMID: 25574791.

20. Leal Ghezzi T, Campos Corleta O. 30 Years of Robotic Surgery. World J Surg. 2016 Oct;40(10):2550-7. doi: 10.1007/s00268-016-3543-9. PMID: 27177648.

21. Letouzey V, Huberlant S, Faillie JL, Prudhomme M, Mares P, de Tayrac R. Evaluation of a laparoscopic training program with or without robotic assistance. Eur J Obstet Gynecol Reprod Biol. 2014 Oct; 181:321-7. doi: 10.1016/j.ejogrb.2014.08.003. Epub 2014 Aug 20. PMID: 25216348.

22. Li JC, Lo AW, Hon SS, Ng SS, Lee JF, Leung KL. Institution learning curve of laparoscopic colectomy--a multi-dimensional analysis. Int J Colorectal Dis.2012Apr;27(4):527-33.doi:10.1007/s00384-011-1358-6. Epub2011 Nov 30. PMID: 22124675

23. Moglia A, Ferrari V, Melfi F, Ferrari M, Mosca F, Cuschieri A, Morelli L. Performances on simulator and da Vinci robot on subjects with and without surgical background. Minim Invasive Ther Allied Technol. 2018 Dec;27(6):309-314. doi: 10.1080/13645706.2017.1365729. Epub 2017 Aug 17. PMID: 28817346.

24. Napoli N, Kauffmann EF, Perrone VG, Miccoli M, Brozzetti S, Boggi U. The learning curve in robotic distal pancreatectomy. Updates Surg 2015 Sep;67(3):257-64. doi: 10.1007/s13304-015-0299-y. Epub 2015 May 20. PMID: 25990666.

25. Parisi A, Scrucca L, Desiderio J, Gemini A, Guarino S, Ricci F, Cirocchi R, PalazziniG, D'AndreaV, Minelli L, TrastulliS. Roboticrighthemicolectomy: Analysis of 108 consecutive proceduresandmultidimensionalassessment of the learning curve. Surg Oncol. 2017 Mar;26(1):28-36. doi: 10.1016/j. suronc.2016.12.005. Epub 2016 Dec 19. PMID: 28317582.

26. Pimentel M, Cabral RD, Costa MM, Neto BS, Cavazzola LT. Does Previous Laparoscopic Experience Influence Basic Robotic Surgical Skills? J Surg Educ. 2018 Jul-Aug;75(4):1075-1081.

27. Shakir M, Boone BA, Polanco PM, Zenati MS, Hogg ME, Tsung A, Choudry HA, Moser AJ, Bartlett outcomes of the first 100 consecutive cases at a high-volume pancreatic centre. HPB (Oxford). 2015 Jul;17(7):580-6. doi: 10.1111/hpb.12412. Epub 2015 Apr 23. PMID: 25906690; PMCID: PMC4474504.

28. Shane MD, Pettitt BJ, Morgenthal CB, Smith CD. Should surgical novices trade their retractors for joysticks? Videogame experience decreases the timeneeded toacquiresurgical skills. Surg Endosc.2008May;22(5):1294-7. doi: 10.1007/s00464-007-9614-0. Epub 2007 Oct 31. PMID: 17972136

29. Singapogu RB, Smith DE, Long LO, Burg TC, Pagano CC, Burg KJ.Objective differentiation of force-based laparoscopic skills using a novel haptic simulator. J Surg Educ. 2012 Nov-Dec;69(6):766-73. doi: 10.1016/j. jsurg.2012.07.008. Epub 2012 Sep 5. PMID: 23111044.

30. Sommer KJ. Pilot training: What can surgeons learn from it? Arab J Urol. 2014 Mar;12(1):32-5. doi: 10.1016/j.aju.2013.08.011. Epub 2013 Sep 17. PMID: 26019919; PMCID: PMC4434512.

31. Søvik TT, Aasheim ET, Kristinsson J, Schou CF, Diep LM, Nesbakken A MalaT.Establishing laparoscopic Roux-en-Ygastricbypass: perioperative outcome and characteristics of the learning curve. Obes Surg. 2009 Feb;19(2):158-165. doi: 10.1007/s11695-008-9584-x. Epub 2008 Jun 20. PMID: 18566869

32. Tapias LF, Morse CR. Minimally invasive Ivor Lewis esophagectomy: description of a learning curve. J Am Coll Surg. 2014 Jun;218(6):1130-40. doi:10.1016/j.jamcollsurg.2014.02.014.Epub2014Feb21.PMID:24698488.

33. Tillou X, Collon S, Martin-Francois S, Doerfler A. Robotic Surgery Simulator: Elements to Build a Training Program. J Surg Educ. 2016 Sep-Oct;73(5):870-8. doi: 10.1016/j.jsurg.2016.04.008. Epub 2016 May 17. PMID: 27211879

34. TORRES, Alberto et al. DEVELOPMENT AND VALIDATION OF A NEW LAPAROSCOPICENDOTRAINERFORNEONATALSURGERYANDREDUCED SPACES. ABCD, arq. Bras. Cir. Dig., 2020, vol.33, no.4. ISSN 0102-6720

35. Tsai KY, Kiu KT, Huang MT, Wu CH, Chang TC. The learning curve for laparoscopic colectomy in colorectal cancer at a new regional hospital. Asian J Surg. 2016 Jan;39(1):34-40. doi: 10.1016/j.asjsur.2015.03.008. Epub 2015 May 7. PMID: 25959025.

36. Wiener S, Haddock P, Shichman S, Dorin R. Construction of a Urologic Robotic Surgery Training Curriculum: How Many Simulator Sessions Are Required for Residents to Achieve Proficiency? J Endourol. 2015 Nov;29(11):1289-93. doi: 10.1089/end.2015.0392. Epub 2015 Aug 25. PMID: 26154108.

37. Zhang H, Chen L, Wang Z, Zheng Y, Geng Y, Wang F, Liu D, He A, Ma L, Yuan $Y$, Wang $Y$. The Learning Curve for Robotic McKeown Esophagectomy in Patients With Esophageal Cancer. Ann Thorac Surg. 2018Apr;105(4):1024-1030.doi:10.1016/j.athoracsur.2017.11.058. Epub 2017 Dec 27. PMID: 29288659.

38. Zhao LY, Zhang WH, Sun Y, Chen XZ, Yang K, Liu K, Chen XL, Wang YG, Song XH, Xue L, Zhou ZG, Hu JK. Learning curve for gastric cancer patientswithlaparoscopy-assisted distal gastrectomy:6-yearexperience from a single institution in western China. Medicine (Baltimore). 2016 Sep;95(37):e4875.doi:10.1097/MD.0000000000004875.PMID:27631257 PMCID: PMC5402600 